\title{
Freshwater snails as the intermediate host of trematodes in Iran: a systematic review
}

\author{
Samira Dodangeh ${ }^{1}$, Ahmad Daryani ${ }^{2}$, Mehdi Sharif ${ }^{2}$, Shirzad Gholami ${ }^{2}$, Elham Kialashaki ${ }^{1}$, \\ Mahmood Moosazadeh ${ }^{3}$, Shahabeddin Sarvi ${ }^{2}$ \\ 'Student Research Committee, Mazandaran University of Medical Sciences, Sari, Iran; '2Department of Medical Parasitology and Mycology, \\ Toxoplasmosis Research Center, Mazandaran University of Medical Sciences, Sari, Iran; ${ }^{3}$ Health Sciences Research Center, Addiction Institute, \\ Mazandaran University of Medical Sciences, Sari, Iran
}

\begin{abstract}
Freshwater snails, as the first intermediate hosts of trematodes, can cause health hazards in animals and humans. Recently, the World Health Organization has included Iran in a list of 6 countries known to have serious problems with fascioliasis. In addition, cercarial dermatitis is a job-related disease that is seen often in paddy workers, agricultural labourers, and fishermen in Iran, particularly in Mazandaran Province. Many studies have been conducted in Iran to survey larval trematodes in freshwater snails. However, to the best of our knowledge, no comprehensive data exist regarding infections in gastropods. Therefore, the aim of the present study was to estimate the types and prevalence of cercarial infections in snails in Iran. Electronic English-language and Persian-language databases were searched to identify 24 published articles reporting the prevalence of trematode infections in snails ( 9 species from 6 families) in various provinces of Iran. In total, $4.4 \%$ of gastropods were infected with the larval stages of trematodes. According to the studies reviewed in this meta-analysis, the highest infection prevalence was found in Radix auricularia (9.9\%). Twelve larval species of trematodes were identified, and the highest prevalence of cercariae was found for Echinostomatidae cercariae (4.3\%). Among the provinces explored, West Azerbaijan had the highest prevalence of infected snails (16.9\%). The presence of trematodes in snails could pose a serious health problem in Iran. Thus, further studies are necessary to characterize these infections in other provinces.
\end{abstract}

KEY WORDS: Meta-analysis, Prevalence, Snail, Trematodes, Iran

\section{INTRODUCTION}

Trematode infections pose serious risks to the health of their vertebrate hosts, including humans and livestock, and can adversely affect both agriculture and the economy [1]. Digenetic trematodes have a complicated life cycle that is initiated in their first intermediate hosts, such as freshwater snails, which are widespread in wa-

\section{Correspondence: Shahabeddin Sarvi}

Department of Medical Parasitology and Mycology, Toxoplasmosis Research Center, Mazandaran University of Medical Sciences, P.O. Box 48175-1665, Sari, Iran

E-mail: shahabesarvi@yahoo.com

Received: Sep 22, 2018 / Accepted: Dec 16, 2018 / Published: Jan 7, 2019

This article is available from: http://e-epih.org/

(C) This is an open-access article distributed under the terms of the Creative Commons Attribution License (http://creativecommons.org/licenses/by/4.0/), which permits unrestricted use, distribution, and reproduction in any medium, provided the original work is properly cited.

(C) 2019, Korean Society of Epidemiology ter sources in most geographical regions; the larval stages, such as sporocysts, rediae, and cercariae, develop within snails [2,3]. Therefore, the extent of human infections is primarily related to the rate of exposure to infective larvae. According to study of Doughty [4] has been reported that most infected people show no overt symptoms of disease. Instead, significant disease is mainly observed in a small subset of people with a heavy burden of trematodes. The distribution of these flukes depends on the availability of intermediate hosts (various snail species).

Three human schistosome species, Schistosoma mansoni, Schistosoma japonicum, and Schistosoma haematobium, are responsible for 200 million infections annually. In addition, cercarial dermatitis is a disease caused by other species of schistosomes, which parasitize mammals (mostly ruminants) and aquatic birds (especially the Anatidae family) [4]. Cercarial dermatitis is a job-related disease that is seen often in paddy workers, agricultural labourers, and fishermen in Iran, particularly in Mazandaran Province [5]. Fasciola hepatica occurs widely in sheep-rearing and cattle-rearing 
areas worldwide, causing severe morbidity and mortality. In Asia, human infections are mainly observed in Iran, and to a lesser extent in Vietnam. The World Health Organization has recently included Iran in a list of 6 countries that are known to have significant problems with fascioliasis [6]. Opisthorchis viverrini and Clonorchis sinensis are common liver flukes found in fish-eating mammals, especially cats and dogs, although humans can become infected by consuming undercooked freshwater fish containing metacercariae of these parasites. Fasciolopsis buski, the giant intestinal fluke, is the etiological agent of fasciolopsiasis in many mammals, particularly humans. Fasciolopsiasis occurs through the consumption of raw or undercooked aquatic plants containing the metacercariae. Paragonimus westermani, a lung fluke, has a wide variety of mammalian hosts, and can also infect humans who ingest insufficiently cooked crabs or crayfish contaminated with the encysted parasite [4].

The dynamics of ecosystems containing snails should be monitored in multiple areas, so that knowledge about the distributions of both the snail population and parasitic diseases in those areas may help to control the snail population, thereby improving community health.

Approximately 350 snail species are known to be of probable medical or veterinary importance. Among the intermediate hosts of trematodes, the species belonging the genera Biomphalaria, $\mathrm{Bu}$ linus (water), and Oncomelania (amphibious) are important in the transmission of human schistosomes. In addition, the most important intermediate hosts of liver flukes are members of the genus Lymnaea, which may be either aquatic or amphibious [7].

According to the available resources, various species of snails are found in different parts of Iran; but the fauna of Iran and relevant parasitic infections have not been extensively examined, unlike in other parts of the world [8].

Many different types of cercariae have been identified. For instance, Anucherngchai et al. [9] reported 9 types of cercarial infections-cercariae, furcocercous cercariae, echinostome cercariae, monostome cercariae, megarulous cercariae, parapleurolophocercous cercariae, pleurolophocercous cercariae, xiphidiocercariae, and virgulate cercariae-in freshwater gastropods from 10 provinces in the Chao-Phraya Basin.

Thus, collecting data on the prevalence of infections with different cercariae in snails is essential for estimating the risk of parasitic diseases in different parts of Iran. In recent years, some studies have been carried out on trematode infections in snails in Iran, but further research is necessary to understand these infections more completely. No relevant systematic review has been conducted about the prevalence of these infections in Iran. We therefore considered it necessary to summarize all available studies on such infections in freshwater snails in the form of a review. The aim of the present study was to estimate the types and prevalence of cercarial infections in snails in Iran. Moreover, this review provides easy access to the available literature and also considers the gaps left by previous studies, which would be beneficial for future researchers.

\section{MATERIALS AND METHODS}

This review was conducted in accordance with the PRISMA (Preferred Reporting Items for Systematic Reviews and MetaAnalyses) guideline for reporting systematic reviews and metaanalyses [10] (Supplementary Material 1).

\section{Search process}

To evaluate trematode cercariae infections in snails in various regions of Iran, we carried out a systematic review of the literature (full-text) published online in the English and Persian languages. Records from 10 databases (PubMed, Science Direct, Web of Science, Scopus, EBSCO, Google Scholar, IranMedex, Magiran, Irandoc, and SID), starting from the first study available (1974) through February 2018, were searched (Figure 1).

To avoid missing any articles, the references of all papers were thoroughly checked. We searched for keywords or subject headings including snail, gastropoda, Mollusca, trematode, Trematoda, and Iran.

\section{Inclusion and exclusion criteria}

All Persian-language and English-language studies that determined the larval stages of trematodes in snails, either microscopically or molecularly, in Iran were included in this review. Studies in which the type of snail infection, the number of infected snails, or the surveyed province was not individually considered were excluded from the review.

\section{Study selection}

Two authors (SD and EK) independently assessed the titles and abstracts of the articles. The full texts of relevant studies were reviewed independently to ensure their eligibility for inclusion in this review. Disagreements were resolved by discussion or by a third researcher (MM).

\section{Quality assessment}

The quality of each study was independently evaluated by 2 authors (SD and MM) according to Newcastle-Ottawa Scale [11] (Supplementary Material 2). This tool includes 3 main sections, the first section is graded on a scale containing 5 stars and mainly assesses the methodological quality of an individual study. The second section is graded from 2 stars and focuses on the comparability of the study. Finally, the third section, which is graded from 3 stars, deals with the outcomes and statistical analysis of the original study. Studies with a score of $50.0 \%$ and above were considered to have high methodological quality.

\section{Data extraction}

Information regarding the species of snails, year of publication, areas of study, number of snails examined, number of infected snails, prevalence of infection, method of study, stage of development, parasites isolated, and first author was extracted from the articles and entered into an Excel spreadsheet (Table 1). 


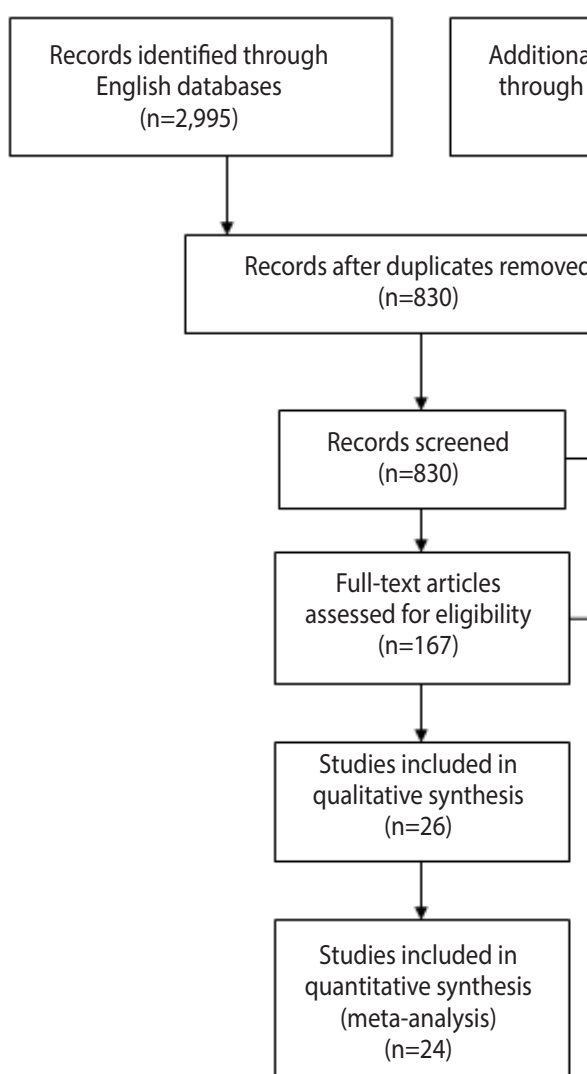

Additional records identified hrough Persian databases $(n=243)$

\section{Data analysis}

StatsDirect statistical software (StatsDirect Ltd., Cambridge, UK) was used for data analysis. For each study, the standard deviation of the prevalence was calculated using a binomial distribution formula. The degree of heterogeneity among the results was determined based on the $\mathrm{Q}$ test and the $\mathrm{I}^{2}$ indicator. $\mathrm{I}^{2}$ indicates the percentage variation between studies attributed to heterogeneity compared to chance. $\mathrm{I}^{2}$ values $\leq 50.0 \%$ indicate low heterogeneity, and $\mathrm{I}^{2}$ values between $50.0 \%$ and $75.0 \%$ suggest moderate heterogeneity. Values $>75.0 \%$ indicate high heterogeneity across studies, meaning that pooled prevalence must have considered by using a random-effects model [12]. To investigate possible sources of heterogeneity, a meta-analysis was performed on some snail species and provinces. Point estimations of the prevalence of infections with $95 \%$ confidence intervals (CIs) are shown in forest plots. The size of each square illustrates the weight of each study, while the crossed lines indicate the CIs. The bias in the results was examined by Begg and Egger tests.

\section{RESULTS}

Of the 2,408 studies identified through the initial search, 24 were included in this systematic review, as shown in Table 1 [8,13-35]. A flowchart describing the study design is shown in Figure 1.

A total of 98,235 freshwater snails of 9 different species from

the families Lymnaeidae, Physidae, Planorbidae, Viviparidae, Thiaridae, and Melanopsidae were collected and identified from different parts of Iran. The prevalence of larval trematodes in the various snail species and areas investigated is shown in Table 1. Additionally, the total quality of all primary studies was greater than 4 , indicating that the quality of the included papers was medium to high.

Considerable variation was present in the number of trematode cercariae-infected snails across studies; the heterogeneity was quite high $(\mathrm{Q}=4,187.3, \mathrm{p}<0.001)$, and the $\mathrm{I}^{2}$ obtained was $99.2 \%$ (Figure 2).

Using a random-effects model for the meta-analysis, 4.4\% (95\% CI, 2.8 to 6.3 ) of the collected gastropods were found to be infected with fluke larvae.

\section{Analysis of bias in the findings}

Publication bias was analyzed using an Egger funnel plot with 95\% CIs. The results of the test (Egger bias: 6.3 [95\% CI, 3.3 to 9.3]; $\mathrm{p}<0.001$ ) strongly suggested publication bias (Figure 3 ).

\section{Infections in gastropods}

The gastropods in all studies belonged to Radix auricularia, Lymnaea palustris, Lymnaea truncatula, Lymnaea stagnalis, Physa gyrina spp., Planorbis planorbis, Bulinus truncatus, Bellamya (Viviparus) bengalensis, Melanoides tuberculata, or Melanopsis spp. Among the snails surveyed in the meta-analysis, the prevalence of trema- 


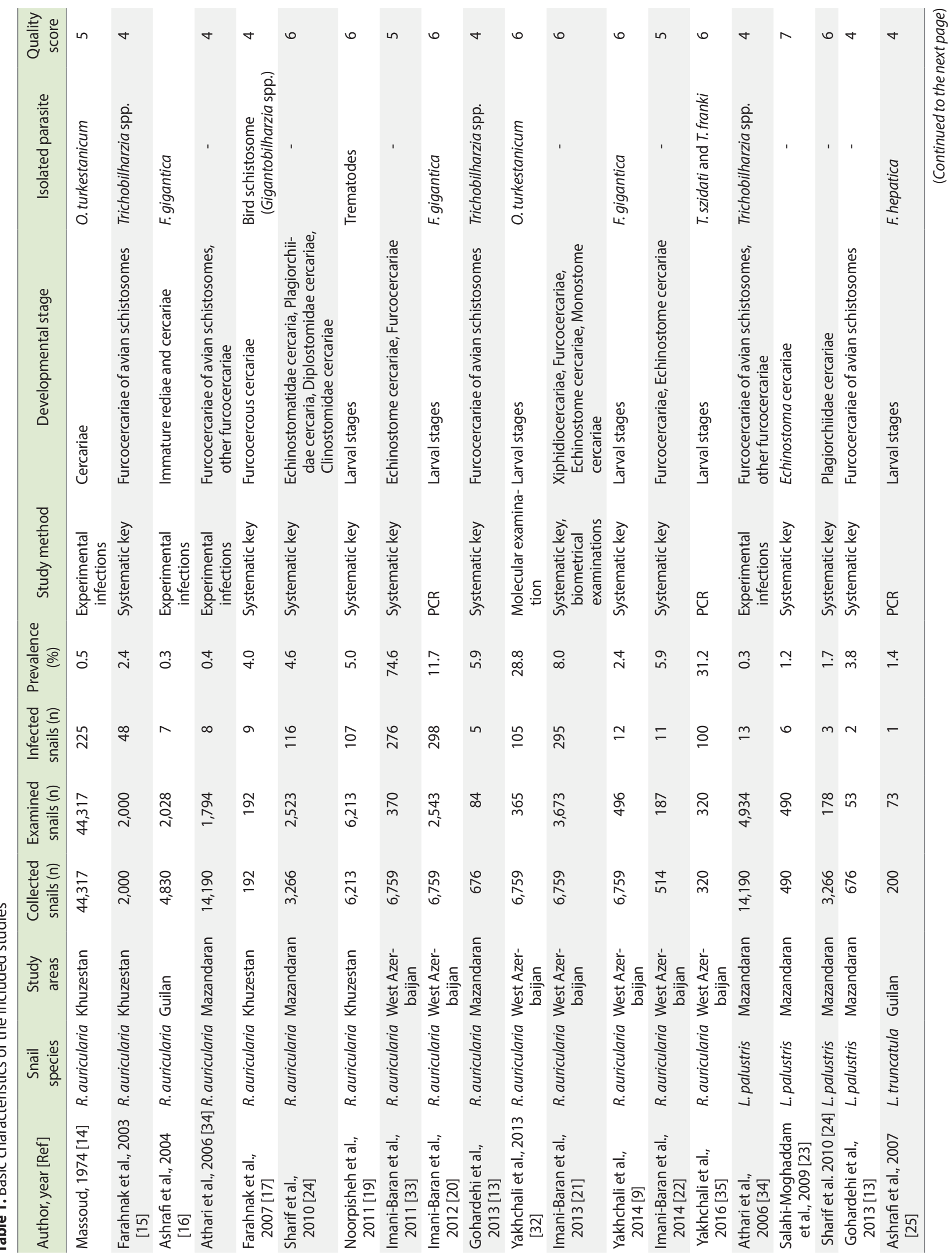




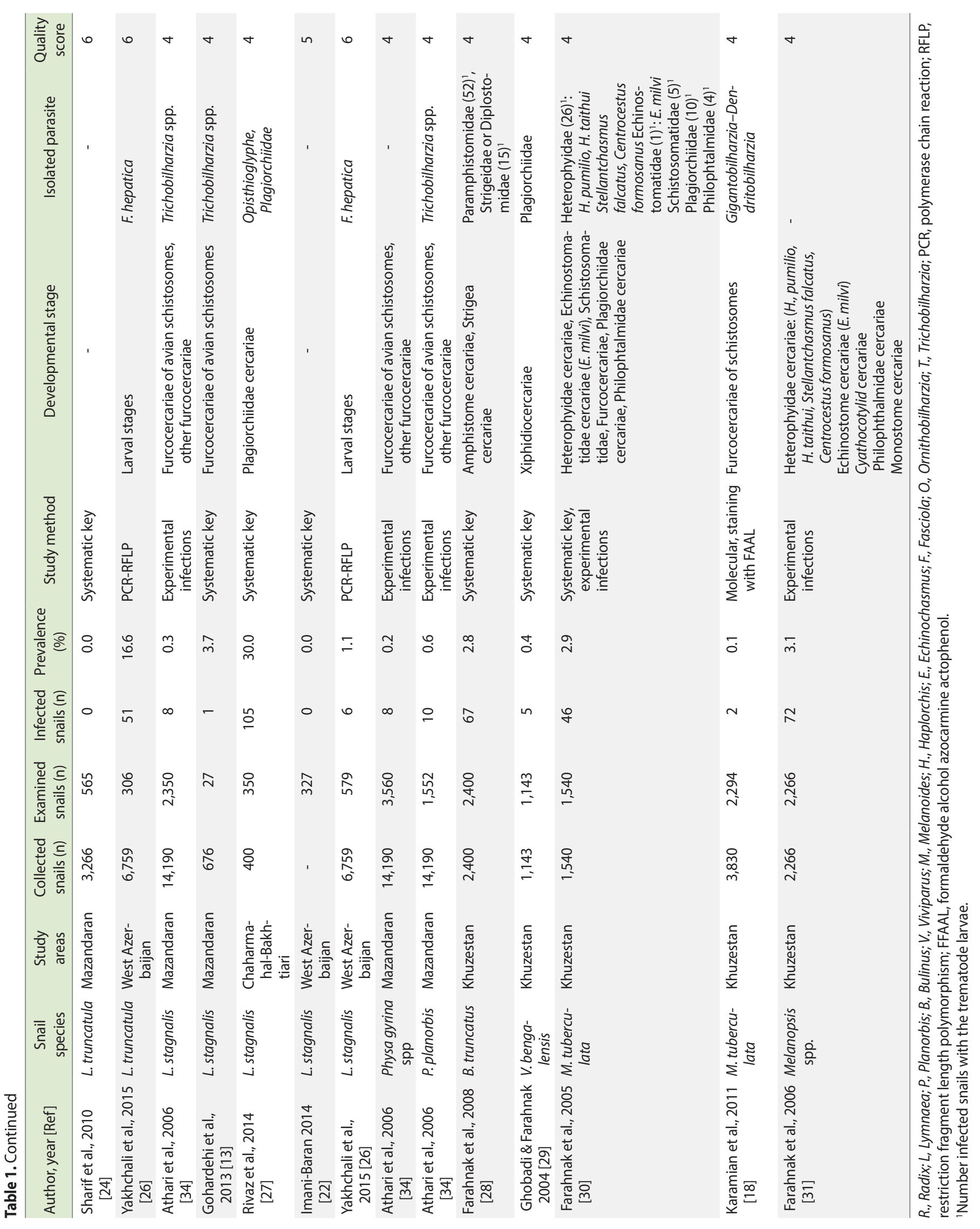


Proportion meta-analysis plot (random effects)

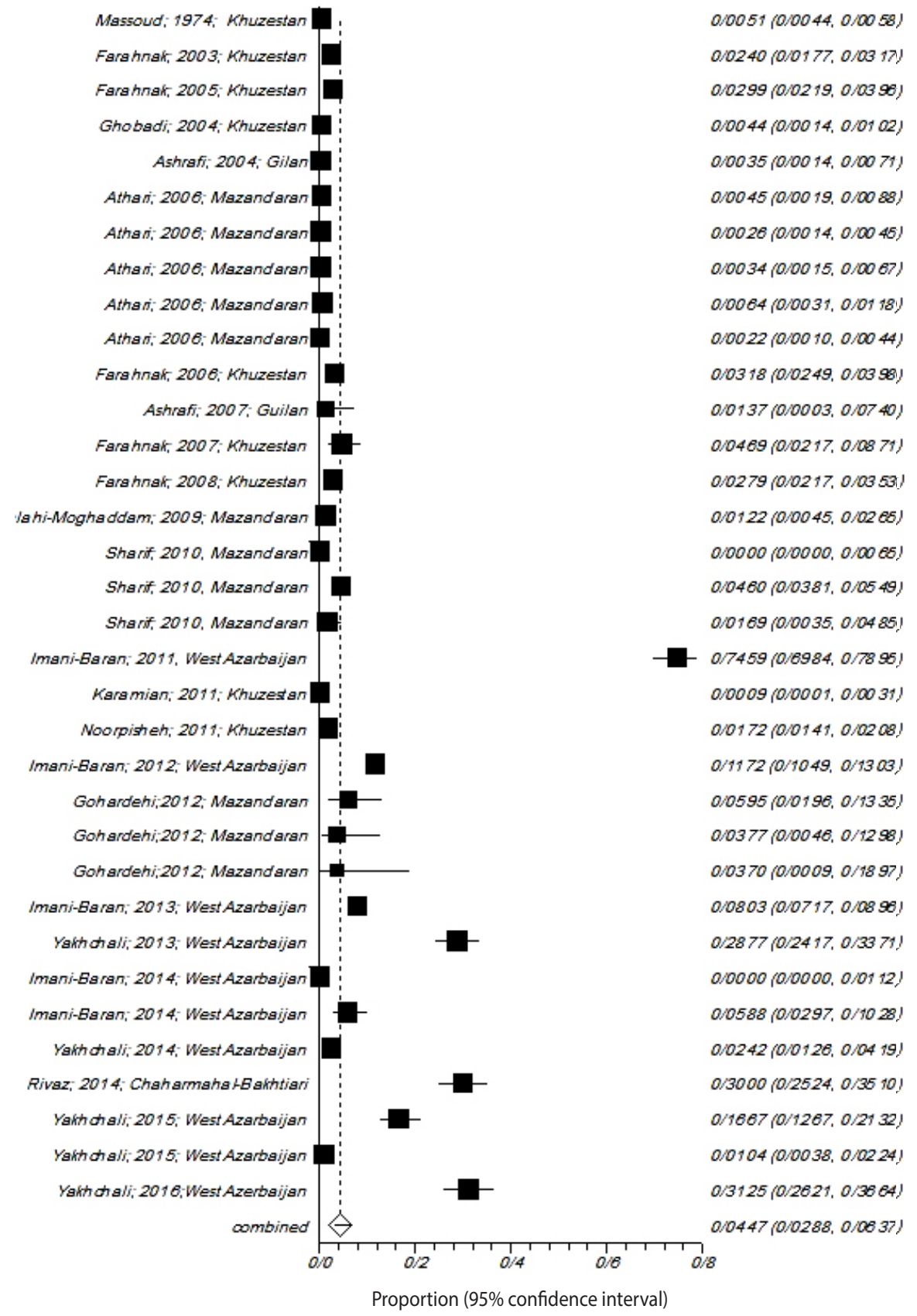

Figure 2. Forest plot diagram of studies showing the prevalence of trematode infections in the examined snails in Iran.

tode infections in R. auricularia was $9.9 \%(\mathrm{p}<0.001, \mathrm{Q}=3,953.6)$, which was greater than that of L. stagnalis and L. palustris, at $3.9 \%$ $(\mathrm{p}<0.001, \mathrm{Q}=343.9)$ and $1.2 \%(\mathrm{p}<0.001, \mathrm{Q}=16.8)$, respectively (Figure 4).

Because other infected snails were investigated in only a few studies, it was not possible to carry out a meta-analysis. Therefore, we present the frequency of infected snails with larval stages of trematodes in Table 2.

\section{Prevalence of larval stages of trematodes in the collected gastropods}

Twelve species of trematode larvae were identified based on systematic keys, biometric examinations, experimental infections (cercariae isolated from snail were transferred into glass petri dishes containing natural water for metacercariae formation; wild-type laboratory mice were orally inoculated with metacercariae, euthanized after 8 weeks, and their livers, peritoneum walls, and abdo- 
minal cavities were checked for adult flukes), molecular examinations (polymerase chain reaction [PCR] or PCR with restriction fragment length polymorphism analysis), and staining with for-

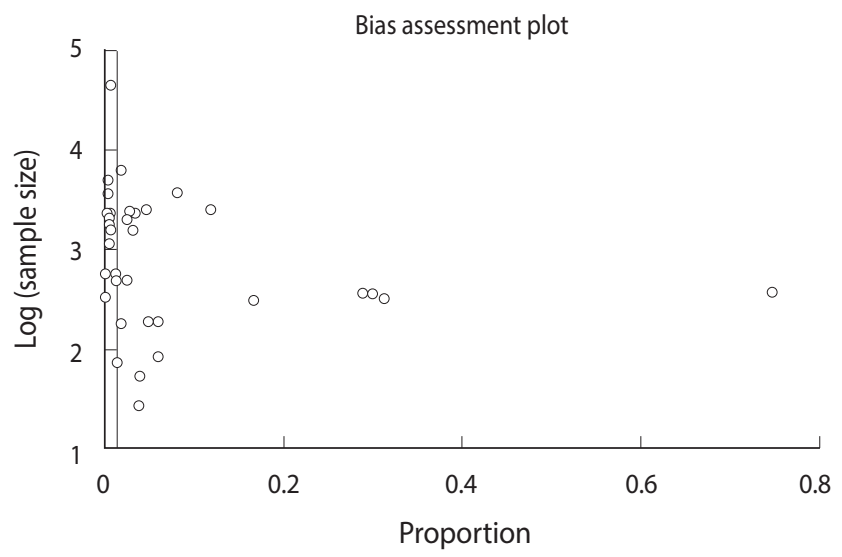

Figure 3. Funnel plot analysis for finding bias.

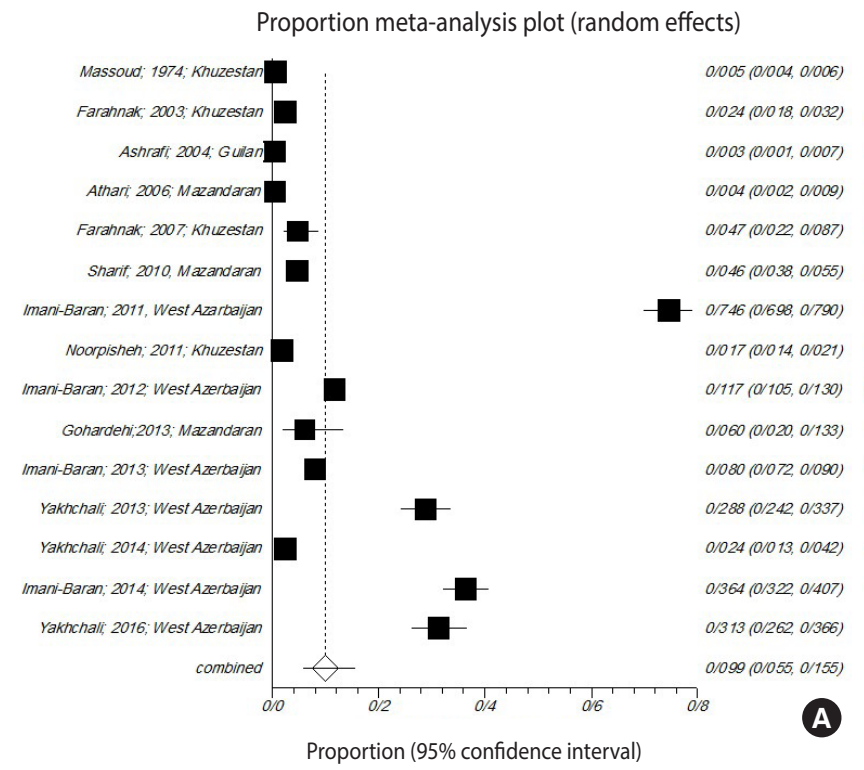

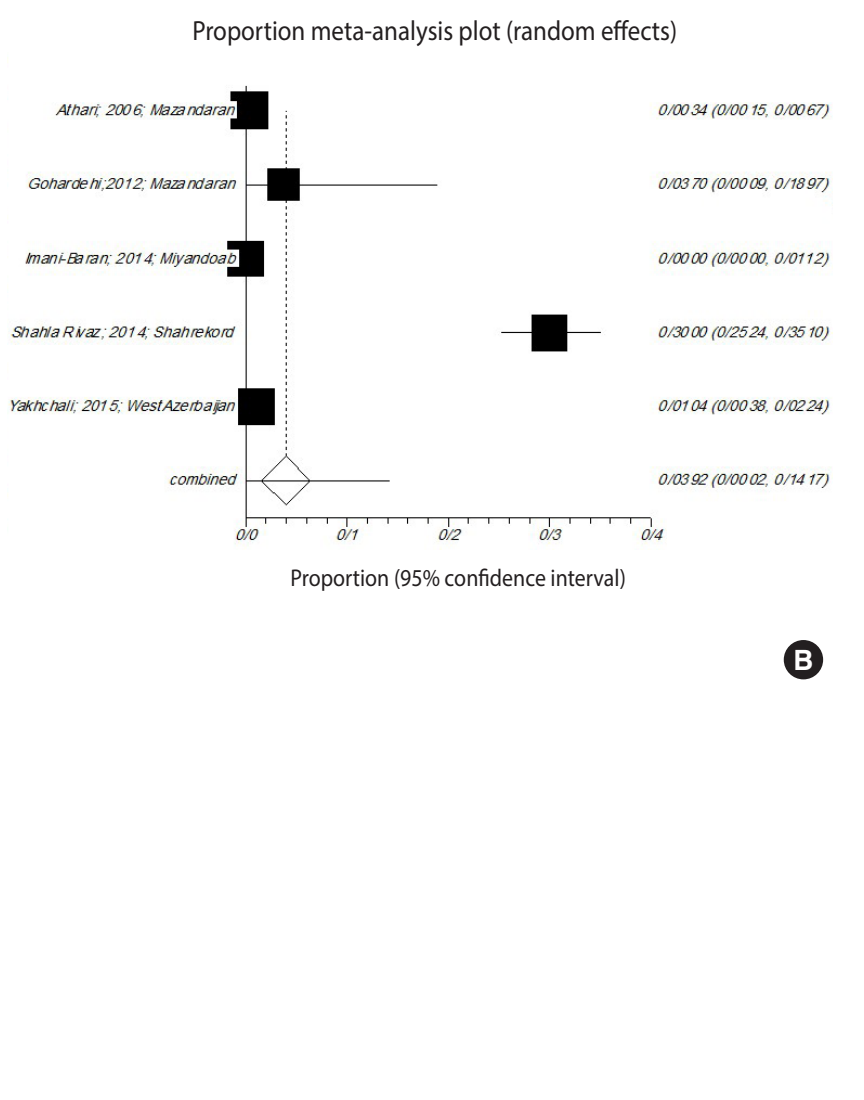

maldehyde alcohol azocarmine lactophenol. Echinostomatidae cercariae (EC), xiphidiocercariae (XC), monostome cercariae (MC), Diplostomidae cercariae (DC), Paramphistomidae cercariae, Strigeidae cercariae, Clinostomidae cercariae (CC), Heterophyidae cercariae, Philophthalmidae cercaria, Cyathocotylidae cercariae, larval stages of Fasciola (FL), and schistosome furcocercariae $(\mathrm{ScF})$ were found in different snails (Table 3).

However, in some studies, the larval stage and parasite species were not evaluated, and only trematode larva or furcocercariae were reported. Among the studies included in the meta-analysis, the highest prevalence of cercariae was found for EC and XC (4.3\% and $4.1 \%$, respectively). The prevalence of other infections is shown in Table 4.

Since the other larval stages were surveyed only in a limited number of studies, it was not possible to conduct a meta-analysis; instead, we used the average number of larval stages, as shown in Table 5.

We found that $R$. auricularia was infected with the largest number of larval trematodes (EC, XC, MC, DC, CC, FL, and ScF). Oth-

Figure 4. Forest plot diagram of studies showing the prevalence of trematode infections in the examined snails (A) Radix auricularia, (B) Lymnaea stagnalis, and (C) Lymnaea palustris in Iran. 
er snails found to be intermediate hosts for different cercariae are shown in Table 3.

\section{Prevalence of infected gastropods in different provinces of Iran}

Freshwater snails were studied in 5 provinces of Iran-West Azerbaijan, Mazandaran, Guilan, Khuzestan, and ChaharmahalBakhtiari-that are important for agriculture.

Table 2. Frequency of infections of snails with larval stages of trematodes in Iran during 1974-2018

\begin{tabular}{lcccc}
\hline Snail types & $\begin{array}{c}\text { Studies } \\
(\mathrm{n})\end{array}$ & $\begin{array}{c}\text { Examined } \\
\text { snails (n) }\end{array}$ & $\begin{array}{c}\text { Infected } \\
\text { snails (n) }\end{array}$ & $\begin{array}{c}\text { Infected } \\
\text { snails (\%) }\end{array}$ \\
\hline Lymnae truncatula & 3 & 944 & 56 & 5.9 \\
Physa gyrina spp. & 1 & 3,560 & 8 & 0.2 \\
Planorbis planorbis & 1 & 1,552 & 10 & 0.6 \\
Viviparus bengalensis & 1 & 1,143 & 5 & 0.4 \\
Bulinus truncatus & 1 & 2,400 & 67 & 2.8 \\
Melanoides tuberculata & 2 & 3,834 & 48 & 1.2 \\
Melanopsis spp. & 1 & 2,266 & 72 & 5.9 \\
\hline
\end{tabular}

In 3 provinces (Khuzestan, Mazandaran, and West Azerbaijan), studies examined the prevalence of snails infected with the larval stages of trematodes. Among these 3 provinces, West Azerbaijan

Table 5. Average number of larval stages isolated from snails in Iran

\begin{tabular}{lccc}
\hline $\begin{array}{c}\text { Larval trematode } \\
\text { stages }\end{array}$ & $\begin{array}{c}\text { Studies } \\
(\mathrm{n})\end{array}$ & $\begin{array}{c}\text { Examined larval } \\
\text { stages }(\mathrm{n})\end{array}$ & $\begin{array}{c}\text { Identified larval } \\
\text { stages }(\mathrm{n})\end{array}$ \\
\hline MC & 2 & 5,939 & 7 \\
DC & 1 & 2,523 & 84 \\
CC & 1 & 2,523 & 2 \\
HC & 2 & 3,806 & 69 \\
PhC & 2 & 3,806 & 9 \\
CyC & 1 & 2,266 & 19 \\
TL & 1 & 6,213 & 107 \\
PC & 1 & 2,400 & 52 \\
SC & 1 & 2,400 & 15 \\
\hline
\end{tabular}

MC, monostome cercariae; DC, Diplostomidae cercariae; CC, Clinostomidae cercariae; $\mathrm{HC}$, Heterophyidae cercariae; PhC, Philophthalmidae cercariae; CyC, Cyathocotylidae cercariae; $\mathrm{TL}$, non-identified trematode larvae; PC, Paramphistomidae cercariae; SC, strigea cercariae.

Table 3. Snail species infected with various larval trematodestages in Iran

\begin{tabular}{|c|c|c|c|c|c|c|c|c|c|c|c|c|c|c|c|}
\hline \multirow[b]{2}{*}{ Snail types } & \multicolumn{15}{|c|}{ No. of cases infected with various larval trematode stages } \\
\hline & $\begin{array}{c}\text { Examined } \\
\text { individuals }(\mathrm{n})\end{array}$ & $\mathrm{EC}$ & $\mathrm{XC}$ & MC & DC & $\mathrm{CC}$ & $\mathrm{HC}$ & $\mathrm{PhC}$ & $\mathrm{CyC}$ & $\mathrm{FL}$ & ScF & PC & SC & $\mathrm{TL}$ & FC \\
\hline R. auricularia & 106,090 & 283 & 271 & 4 & 84 & 2 & - & - & - & 317 & 495 & - & - & 107 & 120 \\
\hline L. palustris & 5,655 & - & 3 & - & - & - & - & - & - & - & 11 & - & - & - & 10 \\
\hline L. truncatula & 944 & - & - & - & - & - & - & - & - & 52 & - & - & - & - & - \\
\hline L. stagnalis & 3,633 & - & 105 & - & - & - & - & - & - & 6 & 2 & - & - & - & 7 \\
\hline Physa gyrina spp. & 3,560 & - & - & - & - & - & - & - & - & - & - & - & - & - & 8 \\
\hline P.planorbis & 1,552 & - & - & - & - & - & - & - & - & - & 1 & - & - & - & 9 \\
\hline B. truncatus & 2,400 & - & - & - & - & - & - & - & - & - & - & 52 & 15 & - & - \\
\hline V. bengalensis & 1,143 & - & 5 & - & - & - & - & - & - & - & - & - & - & - & - \\
\hline M. tuberculata & 3,834 & 1 & 10 & - & - & - & 26 & 4 & - & - & 7 & - & - & - & - \\
\hline Melanopsis spp. & 2,266 & 2 & - & 3 & - & - & 43 & 5 & 19 & - & - & - & - & - & - \\
\hline $\begin{array}{l}\text { Snails examined and infected } \\
\text { with larval stages }\end{array}$ & 131,077 & 286 & 394 & 7 & 84 & 2 & 69 & 9 & 19 & 375 & 516 & 52 & 15 & 107 & 154 \\
\hline
\end{tabular}

R., Radix; L., Lymnaea; P., Planorbis; B., Bulinus; V., Viviparus; M., Melanoides; EC, Echinostomatidae cercariae; XC, xiphidiocercariae; MC, monostomecercariae; DC, Diplostomidae cercariae; CC, Clinostomidae cercariae; HC, Heterophyidae cercariae; PhC, Philophthalmidae cercariae; CyC, Cyathocotylidae cercariae; FL, larval stages of Fasciola; ScF, schistosome furcocercariae; PC, Paramphistomidae cercariae; SC, strigeacercariae; TL, non-identified trematode larvae; FC, non-identified furcocercariae.

Table 4. Data related to forest plot diagrams of studies showing the prevalence of trematode cercariae in Iran

\begin{tabular}{lccccc}
\hline $\begin{array}{c}\text { Trematode larval } \\
\text { stages }\end{array}$ & $\begin{array}{c}\text { Pooled proportion } \\
(\%)\end{array}$ & $\begin{array}{c}\mathrm{I}^{2} \text { (inconsistency), } \\
(95 \% \mathrm{Cl})\end{array}$ & Cochran Q & df & p-value \\
\hline EC & 4.3 & $99.6(99.6,99.7)$ & $1,357.0$ & 5 & $<0.001$ \\
XC & 4.1 & $99.0(98.8,99.1)$ & 485.7 & 5 & $<0.001$ \\
FL & 3.7 & $99.0(98.7,99.2)$ & 390.8 & 4 & $<0.001$ \\
FC & 2.8 & $97.2(96.0,97.9)$ & 143.7 & 4 & $<0.001$ \\
SCF & 2.7 & $98.4(98.2,98.6)$ & 898.1 & 14 & $<0.001$ \\
\hline
\end{tabular}

$\mathrm{Cl}$, confidence interval; EC, Echinostomatidae cercariae; XC, xiphidiocercariae; FL, larval stages of Fasciola; FC, non-identified furcocercariae; ScF, schistosome furcocercariae. 


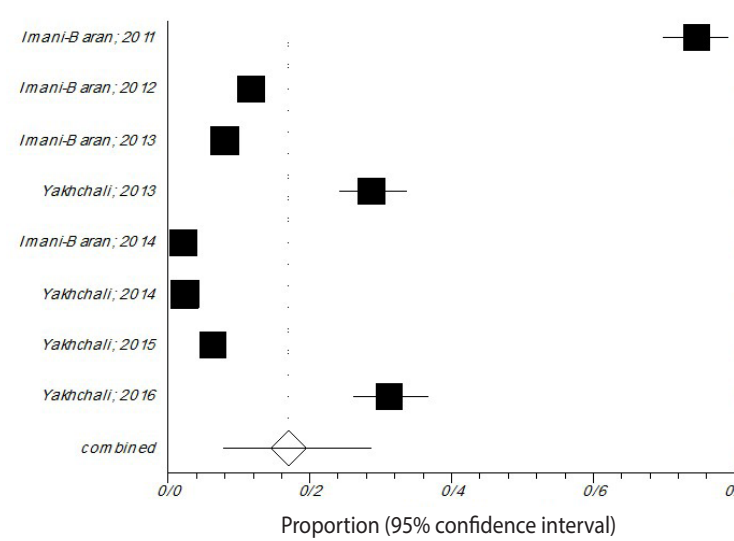

Proportion meta-analysis plot (random effects)

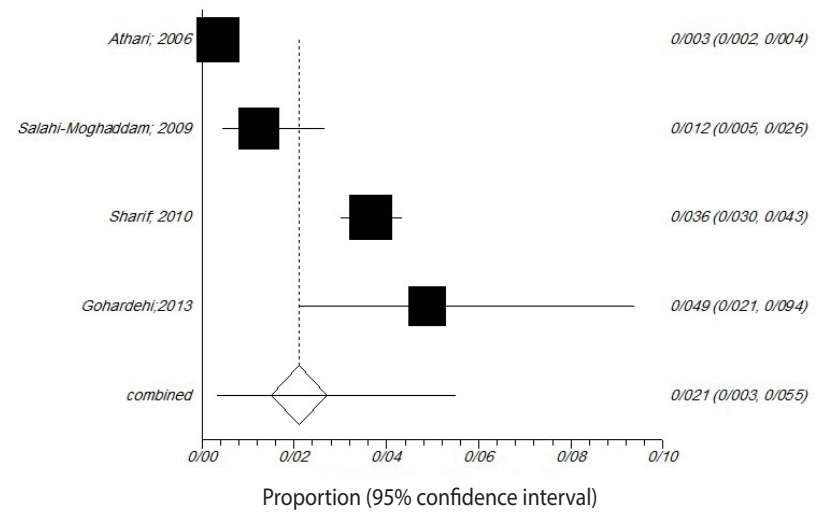

C
Figure 5. Forest plot diagram of studies showing infections of gastropods in, (A) West Azerbaijan; (B) Khuzestan; (C) Mazandaran. showed the highest prevalence of infected snails (16.9\%; 95\% CI, 7.9 to 28.5; $\mathrm{Q}=1,093.6 ; \mathrm{p}<0.001)$. In Khuzestan Province, the pooled proportion was $1.7 \%(95 \% \mathrm{CI}, 0.8$ to $2.7 ; \mathrm{Q}=362.2 ; \mathrm{p}<0.001)$. In Mazandaran Province, the pooled proportion was $2.1 \%$ (95\% CI, 0.3 to 5.4; $\mathrm{Q}=208.0 ; \mathrm{p}<0.001$ ) (Figure 5).

Two studies in Guilan Province, performed by Ashrafi et al. [16,25], showed that 7 of 2,028 (2004) and 1 of 73 (2007) snails were infected with larval stages of Fasciola gigantica and F. hepatica, respectively. Furthermore, 105 of 350 snails examined by Rivaz et al. [27] in Chaharmahal-Bakhtiari Province were found to be infected with Plagiorchiidae cercariae.

\section{DISCUSSION}

To our knowledge, this is the first systematic review of cercarial infections in snails in Iran. In this systematic review and meta-analysis, the overall prevalence of freshwater gastropods infected with cercariae in Iran was estimated to be $4.4 \%$ (95\% CI, 2.8 to 6.3 ). The prevalence of cercarial infections in gastropods has been reported worldwide; similar studies in Turkey, Pakistan, and Iraq have reported high prevalence rates of these infections $(7.3 \%, 14.8 \%$, and $30.7 \%$, respectively) [36-38]. The prevalence in countries such as Tanzania (1.3\%) and France $(1.9 \%)$ is lower $[39,40]$, while the prevalence in Nepal (4.3\%) is similar to that found in our study [41].

Among the snail species surveyed in this meta-analysis, $R$. auricularia (9.9\%) was the most commonly infected. Some gastropods were not included in this meta-analysis because an inadequate number of articles investigated them. Since sequencing of ribosomal DNA ITS-2 demonstrated that Lymnaea (Radix) gedrosiana, which has been reported in many European countries [42], is a synonym of $R$. auricularia (the haplotype reported in Bandar-Anzali, northern Iran), in this study, $R$. auricularia was employed instead. Notably, the larval stages of Echinostomatidae, Monostome, Diplostomidae, Clinostomidae, Plagiorchiidae, Fasciola, and schistosomes were found in R. auricularia.

The prevalence of infections in L. stagnalis, which functions as a host of various trematode larvae, such as Plagiorchiidae, Fascio$l a$, and schistosome larvae, was reported to be 3.9\%. Soldánová et al. [43] reported that $15.1 \%$ of L. stagnalis samples were infected by species from the families Echinostomatidae, Diplostomidae, Plagiorchiidae, Schistosomatidae, and Telorchiidae in the Ruhr River of Germany.

Despite the broad range of data related to the prevalence of cercariae in snails, only 4 types of cercariae could be evaluated by a meta-analysis because of the insufficient number of studies on oth- 
er cercariae. In this review, the prevalence of EC infection in $R$. auricularia, M. tuberculata, and Melanopsis spp. was 4.3\%. This rate is lower than that reported by Abdul-Salam (6.1\%) in a study on Clypeomorus bifasciata in Kuwait [44]. In Bangladesh, EC was also isolated from $R$. auricularia [45].

In general, the presence of EC in various snails indicates the important role of the gastropods in transmission of EC to birds, including aquatic wild birds as well as domesticated birds, in Iran and other countries. Ranjbarbahadory et al. [46], in a study on gastrointestinal helminths of native turkeys in Amol, Iran, recorded a prevalence of Echinostoma of 11.0\%. Humans become infected by eating the infected freshwater gastropods. Echinostomiasis is endemic in East and Southeast Asia; however, Ahmadi et al. [47] recorded a $0.9 \%$ prevalence of Echinostoma spp. in rehabilitation centers in Mazandaran Province in northern Iran.

In this study, the prevalence of XC in various gastropod species was found to be $4.1 \%$. Parasites isolated from L. stagnalis, L. palustris, $V$. bengalensis, and $M$. tuberculata were from the Plagiorchiidae family. In a study of freshwater resources in Poland, the Plagiorchiidae family was detected in Lymnaeid gastropods [48]. Species of Plagiorchis (family: Plagiorchiidae) have been reported as intestinal trematodes in birds, reptiles, and mammals. Human infections due to Plagiorchis spp. are rare; at present, only 11 cases have been found in humans worldwide [49]. Furthermore, XC generally belong to the Heterophidae, Opisthorchidae, and Fascolidae families, which underscores the veterinary relevance of these snails. It is very unlikely for humans to be infected by these parasites under normal conditions [50].

In Iran, especially in the coastal areas of the Caspian Sea and Persian Gulf, animal fascioliasis has been prevalent over the past 50 years. Despite the high incidence of livestock infections in the southern regions over the past decades, infections in humans have often occurred in the northern provinces, especially in Guilan Province [51]. The 2 species of Fasciola show variant Lymnaeid snail hosts. F. gigantica is transmitted by species of the Radix genus, while F. hepatica is mostly transmitted by species of the Galba/Fossaria genera [42]. In France, L. neotropica, L. viatrix var. ventricosa, and Galba truncatula are known to be hosts of F. hepatica [52]. It is noteworthy that human fascioliasis has emerged as a public health problem in Kermanshah Province in western Iran; hence, the verification of new regions of human fascioliasis requires complementary investigations [53].

Both mammalian and bird schistosomes are causative agents of human cercarial dermatitis, but bird schistosomes, mostly Trichobilharzia species, are responsible for the majority of dermatitis outbreaks reported both in Iran and worldwide [13,54]. Recently, in a study conducted in Mazandaran Province, Iran in 2016, Fakhar et al. [55] reported that all the examined samples of nasal schistosomes were grouped in a sister clade to the European Trichobilharzia regenti.

In Mazandaran Province, Gohardehi et al. [13] showed that the prevalence of infections with Trichobilharzia spp. among migratory birds (ducks) was $15.8 \%$ and the most infected snail was $R$. au- ricularia. In addition, in 2013, Rahimi-Esboei et al. [56] reported a high prevalence $(77.5 \%)$ of cercarial dermatitis among paddy field workers in Mazandaran Province, thereby proving it to be a health hazard in the area. In this review, schistosome furcocercariae were detected in 5 snail species: $R$. auricularia, L. palustris, $L$. stagnalis, $P$. planorbis, and M. tuberculata, with a prevalence of $2.7 \%$. The prevalence of furcocercariae in Bulinus globosus (1.1\%) in Tanzania [39] was less than that found in our study. Bulinus spp. act as intermediate hosts in the life cycle of S. haematobium; despite their remarkable abundance, only a single study, by Farahnak et al. [28], has surveyed infections by trematodes in Bulinus spp. [57].

In this study, different cercariae were detected in several provinces of Iran because of variations in rainfall, humidity, and temperature in each province. Among the provinces evaluated in this meta-analysis, the highest and lowest proportions of cercarial infections were observed in West Azerbaijan (16.9\%) and Khuzestan (1.7\%) Provinces, respectively. Temperatures of $25-30^{\circ} \mathrm{C}$, annual rainfall exceeding $100 \mathrm{~mm}$, and relative humidity $>65.0 \%$ are favorable for the growth and shedding of cercariae [58]. These conditions facilitate their development and growth in host snails, and they change from miracidia to sporocysts, rediae, and eventually cercariae. The climate in West Azerbaijan is mainly influenced by the rain-bearing winds of the Mediterranean Sea and Atlantic Ocean [59]. The mean temperature ranges from $13.7^{\circ} \mathrm{C}$ (winter) to $22.5^{\circ} \mathrm{C}$ (summer), with an average annual rainfall of $300 \mathrm{~mm}$ $800 \mathrm{~mm}$ that occurs in 2 primary rainy seasons (March to June and October to November) and a humidity of $30-80 \%$, indicating that it has a moderate climate. Additionally, West Azerbaijan contains 30 permanent and seasonal wetlands and many suitable habitats for birds. This province is also geographically positioned along the migration path of birds that migrate from northern latitudes to southern latitudes every year at the beginning of the autumn and cold seasons. In previous studies in the province, snails were collected from May through November. The most prevalent cercarial types in the province, according to the reports by ImaniBaran et al. [33] and Yakhchali et al. [35], were EC (276 of 370), T. szidati, and T. franki (100 of 320) from R. auricularia, respectively. Thus, contamination by these two trematodes may be significant in West Azerbaijan. In Chaharmahal-Bakhtiari, 105 of 350 snails surveyed by Rivaz et al. [27] were infected with Plagiorchiidae cercariae.

Some limitations should be considered when interpreting the results of our study, including publication bias. The present metaanalysis only included published studies; we did not search for unpublished studies or original data. Thus, the findings of the Egger funnel plot should be interpreted with caution, because of the few numbers of included studies in combination with the high heterogeneity across the studies, which could limit the ability to assess publication bias.

Few studies have been conducted in Iran, compared to other parts of the world, of the distribution of types of snails and the prevalence of trematode infections in intermediate hosts using 
conventional microscopic and molecular methods. Therefore, due to the limited number of studies carried out in 5 provinces, we could not conduct a meta-analysis of all surveyed provinces, snails, and trematode infections.

\section{CONCLUSION}

This is the first study to provide information on the distribution of various snails, their trematode infections, and their potential to cause zoonotic diseases in Iran. According to the present review, snail control is essential for reducing the prevalence of diseases such as echinostomiasis, fascioliasis, and cercarial dermatitis in humans. Implementation of snail control depends on several factors, such as the infection level in the final hosts (domestic animals or people), the freshwater snail habitat, transmission pattern, snail species, and ecological concerns.

Future studies are needed to characterize the prevalence of trematodes in snails in different provinces of Iran. It is also recommended that more accurate methods should be used for identifying cercariae at the species level, to promote a better understanding of the epidemiological conditions of these infections in different provinces.

\section{SUPPLEMENTARY MATERIALS}

Supplementary materials are available at http://www.e-epih.org/.

\section{CONFLICT OF INTEREST}

The authors have no conflicts of interest to declare for this study.

\section{ACKNOWLEDGEMENTS}

The authors would like to express their deep appreciation for the kind collaboration of Dr. Seyed Abdollah Hosseini, as well as the Student Research Committee, Mazandaran University of Medical Sciences, Sari, Iran for generous support of this study. This study was financially supported by the Vice-Chancellor of Mazandaran University of Medical Sciences (No. 2926).

\section{ORCID}

Samira Dodangeh: http://orcid.org/0000-0002-9450-938X; Ahmad Daryani: https://orcid.org/0000-0001-8571-5803; Shirzad Gholami: https://orcid.org/0000-0003-2429-7702; Shahabeddin Sarvi: https://orcid.org/0000-0002-3412-1033

\section{REFERENCES}

1. Yakhchali M, Ghobadi K. Survey of liver helminthes infection rate and economic loss in sheep in Urmia slaughterhouse. SciRes Iran Vet J 2005;9:60-66 (Persian).

2. Curtis LA. Larval trematode infections and spatial distributions of snails. Invertebr Biol 2007;126:235-246.

3. Skála V, Bulantová J, Walker AJ, Horák P. Insights into the development of Notocotylus attenuatus (Digenea: Notocotylidae) in Lymnaea stagnalis: from mother sporocyst to cercariae. Parasitol Int 2014;63:94-99.

4. Doughty BL. Schistosomes and other trematodes. In: Baron S, editor. Medical microbiology. 4th ed. Galveston: University of Texas Medical Branch at Galveston; 1996, chapter 88.

5. Ghobaditara M, Fakhar M, Karamian M, Sharif M. An overview on present situation of cercarial dermatitis: a neglected zoonotic disease in Iran and the world. J Mazandaran Univ Med Sci 2015; 24:446-460 (Persian).

6. World Health Organization. The "neglected" neglected worms. Action against worms; 2007 [cited 2019 Feb 11]. Available from: https://www.who.int/neglected_diseases/preventive_chemotherapy/Newsletter10.pdf.

7. Rozendaal JA; World Health Organization. Chapter 8: freshwater snails; 1997 [cited 2019 Feb 11]. Available from: https://www. who.int/water_sanitation_health/resources/vector337to356.pdf.

8. Yakhchali M, Malekzadeh-Viayeh R, Imani-Baran A. PCR-RFLP analysis of $28 \mathrm{SrDNA}$ for specification of Fasciola gigantica (Cobbold, 1855) in the infected Lymnaea auricularia (Linnaeus, 1785) snails from Northwestern Iran. Iran J Parasitol 2014;9:358-364.

9. Anucherngchai S, Tejangkura T, Chontananarth T. Epidemiological situation and molecular identification of cercarial stage in freshwater snails in Chao-Phraya basin, Central Thailand. Asian Pac J Trop Biomed 2016;6:539-545.

10. Moher D, Liberati A, Tetzlaff J, Altman DG; PRISMA Group. Preferred reporting items for systematic reviews and meta-analyses: the PRISMA statement. J Clin Epidemiol 2009;62:1006-1012.

11. Wells GA, Shea B, O'Connell D, Peterson J, Welch V, Losos M, et al. The Newcastle-Ottawa Scale (NOS) for assessing the quality of nonrandomised studies in meta-analyses; 2012 [cited 2019 Feb 11]. Available from: http://www.ohri.ca/programs/clinical_epidemiology/oxford.asp.

12. Higgins JP, Thompson SG. Quantifying heterogeneity in a metaanalysis. Stat Med 2002;21:1539-1558.

13. Gohardehi S, Fakhar M, Madjidaei M. Avian schistosomes and human cercarial dermatitis in a wildlife refuge in Mazandaran Province, northern Iran. Zoonoses Public Health 2013;60:442447.

14. Massoud J. Observations on Lymnaea gedrosiana, the intermediate host of Ornithobilharzia turkestanicum in Khuzestan, Iran. J Helminthol 1974;48:133-138.

15. Farahnak A, Essalat M. A parasitological and clinical survey on cercarial dermatitis in Khuzestan Province, south western Iran. Iran J Public Health 2003;32:64-67.

16. Ashrafi K, Massoud J, Holakouei K, Mahmoodi M, Joafshani M, Valero M, et al. Evidence suggesting that Fasciola gigantica might be the most prevalent causal agent of fascioliasis in northern Iran. Iran J Public Health 2004;33:31-37.

17. Farahnak A, Moebedi I. Morphological specifications of the bird schistosome cercariae and surface carbohydrates as receptors for 
lectins. Iran J Parasitol 2007;2:23-28.

18. Karamian M, Aldhoun JA, Maraghi S, Hatam G, Farhangmehr B, Sadjjadi SM. Parasitological and molecular study of the furcocercariae from Melanoides tuberculata as a probable agent of cercarial dermatitis. Parasitol Res 2011;108:955-962.

19. Noorpisheh S, Farahnak A. Determination of the infection of Lymnaea-gedrosina to trematodes Larval in the water region of Khuzestan. J Fasa Univ Med Sci 2011;1:9-12 (Persian).

20. Imani-Baran A, Yakhchali M, Malekzadeh Viayeh R, Paktarmani R. Molecular study for detecting the prevalence of Fasciola gigantica in field-collected snails of Radix gedrosiana (Pulmonata: Lymnaeidae) in northwestern Iran. Vet Parasitol 2012;189:374-377.

21. Imani-Baran A, Yakhchali M, Malekzadeh-Viayeh R, Farahnak A. Seasonal and geographic distribution of cercarial infection in Lymnaea gedrosiana (Pulmunata: Lymnaeidae) in north west Iran. Iran J Parasitol 2013;8:423-429.

22. Imani Baran A. Survey of population changes and cercarial infection of Lymnaea spp freshwater snails. in Miyandoab region, west Azarbaijan Province in 2010. J Rafsanjan Univ Med Sci 2014;13: 581-596 (Persian).

23. Salahi-Moghaddam A, Mahvi AH, Mowlavi G, Hosseini-Chegini A, Massoud J. Parasitological study on Lymnaea palustris and its ecological survey by GIS in Mazandaran province. Pathobiol Res 2009;11:65-71 (Persian).

24. Sharif M, Daryani A, Karimi SA. A faunistic survey of cercariae isolated from Lymnaeid Snails in central areas of Mazandaran, Iran. Pak J Biol Sci 2010;13:158-163.

25. Ashrafi K, Massoud J, Naieni KH, Jo-Afshani MA, Mahmoodi M, Ebadati N, et al. Nuclear ribosomal DNA ITS-2 sequence characterization of Fasciola hepatica and Galba truncatula. Iran J Public Health 2007;36:42-49.

26. Yakhchali M, Baran AI, Malekzadeh-Viayeh R. Molecular detection of the infection with Fasciola hepatica in field-collected snails of Galba truncatula and Lymnaea stagnalis from West Azarbaijan, Iran. Arch Razi Inst 2015;70:195-202.

27. Rivaz S, Karimi G, Nasiri V, Abdigoudarzi M, Paykari H, Rivaz K. Lymnaea stagnalis snails infection in trematoda larval of Shahrekord city springs. Iran J Infect Dis Trop Med 2014;19:31-35 (Persian).

28. Farahnak A, Mobedi I, Eshraghian MR. The use of cercariae infection of the Bulinus truncatus snail for evaluation of schistosomiasis control in Iran. Ann Saudi Med 2008;28:59.

29. Ghobadi H, Farahnak A. A faunistic survey on the cercariae of Bellamya (Viviparus) bengalensis snails and their zoonotic importance. Iran J Public Health 2004;33:38-42.

30. Farahnak A, Setodeh S, Mobedi I. A faunistic survey of cercariae isolated from melanoides tuberculata and their role in transmission diseases. Arch Razi Inst 2005;59:113-119.

31. Farahnak A, Vafaie-Darian R, Mobedi I. A faunistic survey of cercariae from fresh water snails: melanopsis spp. and their role in transmission diseases. Iran J Public Health 2006;35:70-74.

32. Yakhchali M, Mirrajei SY, Malekzadeh-Viayeh R. Detection of infection with larval stages of Ornithobilharzia turkestanicum us- ing PCR in field-collected snails of Lymnaea gedrosiana from northwestern Iran. Iran J Parasitol 2013;8:627-633.

33. Imani-Baran A, Yakhchali M, Malekzadeh Viayeh R, Farhangpajuh F. Prevalence of cercariae infection in Lymnaea auricularia (Linnaeus, 1758) in northwest of Iran. Vet Res Forum 2011;2:121127.

34. Athari A, Gohar-Dehi S, Rostami-Jalilian M. Determination of definitive and intermediate hosts of cercarial dermatitis-producing agents in northern Iran. Arch Iran Med 2006;9:11-15.

35. Yakhchali M, Hosseinpanahi A, Malekzadeh-Viayeh R. Molecular evidence of Trichobilharzia species (Digenea: Schistosomatidae) in the snails of Lymnaea auricularia from Urmia suburb, north west Iran. Iran J Parasitol 2016;11:296-302.

36. Kaplan M, Kelestemur N, Saglam N, Gokhan HB, Baspinar S. Natural larval Trematode infections in Lymnea truncatula populations in Elazig Province in Turkey. J Anim Vet Adv 2012;11: 2356-2358

37. Mohammad MK. The parasitic infection of the freshwater snails collected in central Iraq. Int J Curr Microbiol App Sci 2015;4:4755.

38. Qureshi AW, Tanveer A, Maqbool A, Niaz S. Prevalence and trematode infection of freshwater snails with emphasis on fasciolosis in Punjab, Pakistan. Asian J Agri Biol 2015;3:145-154.

39. Kigadye ES, Nkwengulila G. The occurrence of digenean larvae in freshwater snails at Mbezi-Temboni pond, Dar es Salaam. Tanzan J Sci 2001;27:57-64.

40. Rondelaud D, Vignoles P, Dreyfuss G. Larval trematode infections in Lymnaea glabra populations living in the Brenne Regional Natural Park, central France. Parasite 2015;22:38.

41. Devkota R, Budha PB, Gupta R. Trematode cercariae infections in freshwater snails of Chitwan district, central Nepal. Himalayan J Sci 2011;7:9-14.

42. Ashrafi K, Mas-Coma S. Fasciola gigantica transmission in the zoonotic fascioliasis endemic lowlands of Guilan, Iran: experimental assessment. Vet Parasitol 2014;205:96-106.

43. Soldánová M, Selbach C, Sures B, Kostadinova A, Pérez-Del-Olmo A. Larval trematode communities in Radix auricularia and Lymnaea stagnalis in a reservoir system of the Ruhr River. Parasit Vectors 2010;3:56.

44. Abdul-Salam J. Seasonal prevalence of trematode cercariae in Clypeomorus bifasciata (Gastropoda: Prosobranchia) in Kuwait Bay. Folia Parasitol 1994;41:247-252.

45. Islam Z, Alam MZ, Akter S, Roy BC, Mondal MM. Distribution patterns of vector snails and trematode cercaria in their vectors in some selected areas of Mymensingh. J Environ Sci Natural Resources 2012;5:37-46.

46. RanjbarBahadory S, Hoghoghi Rad N, Ramezani A, Babazadeh D, Falah S, Ghavami S. Evaluation of gastrointestinal helminths of native turkeys in Amol, Iran. J World Poult Res 2014;4:86-88.

47. Ahmadi M, Beigom Kia E, Rezaeian M, Hosseini M, Kamranrashani M, Tarighi F. Prevalence of Strongyloides stercoralis and other intestinal parasites in rehabilitation centers in Mazandaran Province, northern Iran. J Mazandaran Univ Med Sci 2015;25:1-7 
(Persian).

48. Zbikowska E. Digenea species in chosen populations of freshwater snails in northern and central part of Poland. Wiad Parazytol 2007;53:301-308.

49. Hong SJ, Ahn JH, Woo HC. Plagiorchis muris: recovery, growth and development in albino rats. J Helminthol 1998;72:251-256.

50. Massoud J, Jalali H, Reza M. Studies on trematodes of the family Heterophyidae (Odhner, 1914) in Iran: 1. Preliminary epidemiological surveys in man and carnivores in Khuzestan. J Helminthol 1981;55:255-260.

51. Ashrafi K. The status of human and animal fascioliasis in Iran: a narrative review article. Iran J Parasitol 2015;10:306-328.

52. Sanabria R, Mouzet R, Courtioux B, Vignoles P, Rondelaud D, Dreyfuss $\mathrm{G}$, et al. Intermediate snail hosts of French Fasciola hepatica: Lymnaea neotropica and Lymnaea viatrix are better hosts than local Galba truncatula. Parasitol Res 2012;111:2011-2016.

53. Hatami H, Asmar M, Masoud J, Mansouri F, Namdaritabar H, Ramazankhani A. The first epidemic and new-emerging human fascioliasis in Kermanshah (western Iran) and a ten-year follow up, 1998-2008. Int J Prev Med 2012;3:266-272.
54. Horák P, Mikeš L, Lichtenbergová L, Skála V, Soldánová M, Brant SV. Avian schistosomes and outbreaks of cercarial dermatitis. Clin Microbiol Rev 2015;28:165-190.

55. Fakhar M, Ghobaditara M, Brant SV, Karamian M, Gohardehi S, Bastani R. Phylogenetic analysis of nasal avian schistosomes (Trichobilharzia) from aquatic birds in Mazandaran Province, northern Iran. Parasitol Int 2016;65:151-158.

56. Rahimi-Esboei B, Fakhar M, Ghorbani A, Pour Haji Baqer M, Paqeh AS, Shahnasi P, et al. Prevalence of cercarial dermatitis among paddy-field workers in Central areas of Mazandaran Province. Med Lab J 2013;7:49-52 (Persian).

57. Nouroozi RV. Identification of medically important snails of miangran lake in Izeh, Khuzestan Province of Iran. Avicenna J Clin Microbiol Infect 2015;2:e30460.

58. Rahman MH, Begum N, Alim A. Factors for the development of Furcocercus and other cercariae in snails and their release. Bangladesh Vet 1997;14:29.

59. Saboor Yaraghi A, Farahnak A, Eshraghian M. Haemolymph components of infected \& none infected Lymnaea snails with Xiphidiocercariae. Iran J Parasitol 2011;6:86-91. 